\title{
Dinâmica da eliminação de ovos por nematódeos gastrintestinais, durante o periparto de vacas de corte, no Estado do Pará
}

\author{
Parasitic dynamics of gastrointestinal nematode infection in the periparturient \\ period of beef cattle in the State of Para \\ Rinaldo Batista Viana ${ }^{1 *}$; Jean Pierre Brasileiro Bispo²; Cláudio Vieira de Araújo; \\ Raimundo Nonato Moraes Benigno ${ }^{1}$; Bruno Moura Monteiro'; Solange Maria Gennari ${ }^{3}$ \\ ${ }^{1}$ Instituto da Saúde e Produção Animal, Universidade Federal Rural da Amazônia - UFRA \\ ${ }^{2}$ Médico Veterinário Brasnorte Agropecuária \\ ${ }^{3}$ Faculdade de Medicina Veterinária e Zootecnia - USP
}

Recebido em 25 de Março de 2009

Aceito em 1 de Julho de 2009

\section{Resumo}

O experimento foi realizado com o objetivo de investigar a dinâmica da infecçâo por nematódeos gastrintestinais em vacas no periparto. Utilizaram-se 106 vacas de corte, divididas em dois grupos: o grupo 1 (G1), constituído por 42 vacas de primeira e segunda cria; e o grupo 2, (G2) por 76 vacas de terceira cria ou mais. A partir dos 120 dias do pré-parto até os 90 dias pós-parto, coletaram-se fezes para contagens de ovos por grama de fezes (OPG) e sangue para determinaçáo do volume globular e hemoglobina de cada um dos animais a intervalos mensais. Nos mesmos intervalos, avaliaram-se os escores de condição corporal (ECC). Os valores médios \pm desvios-padrão de OPG para os animais do grupo 1 foram iguais a 19,4 $\pm 42,9$, enquanto para os do grupo 2 foram de $31,1 \pm 68,0$ não havendo diferenças significativas entre eles, tampouco entre os valores hematológicos que permaneceram nos padrões normais para ambos os grupos. Maiores contagens de OPG foram observadas no período pós-parto, com médias de 32,5 \pm 55,5e 51,5 \pm 84,8 para os grupos G1 e G2, respectivamente. Observou-se diferença significativa $(\mathrm{p}<0,05)$ nos parâmetros estudados, quando foram comparados os períodos pré e pós-parto dentro de cada um dos grupos, com diminuição dos valores hemáticos e escore corporal e aumento dos valores de OPG no pós-parto. Os resultados sugerem que as vacas podem estar mais susceptíveis à infecçáo por nematoides desde o parto até os 90 dias pós-parto; todavia, vacas adultas, quando bem manejadas, não constituem fator importante na epidemiologia das verminoses gastrintestinais, mesmo no período pós-parto.

Palavras-chave: Bovinos, helmintos, periparto, dinâmica parasitária.

\begin{abstract}
The experiment was conducted to investigate the dynamics of infection by gastrointestinal nematodes during the periparturition period in cows. One hundred and six beef cows were divided into two groups: G1 was formed by 42 cows of one and two parturitions, and G2 by 76 cows of three or more parturitions. From the 120 days pre partum until the 90 days post partum, feces were collected for faecal egg counts (EPG) while blood was collected to determine the packed cell volume and hemoglobin levels of each animal, with monthly intervals. In the same intervals the body condition scores (BCS) were evaluated. The mean values \pm standard deviation of the EPG for G1 were equal to $19.4 \pm 42.9$, and for G2 $31.1 \pm 68.0$. No significant differences were observed between G1 and G2 in relation to EPG and hematological parameters, which remained within normal patterns for both groups. The two groups had higher counts of EPG in the post partum period than in the pre partum period, with averages of $32.5 \pm 55.5$ and $51.5 \pm 84.8$ for groups $G 1$ and G2, respectively. A significant difference $(p<0.05)$ in the parameters was observed when comparing the pre and post partum within each group studied resulting in declining values of blood and body score and an increase in EPG in the post partum. The results suggest that the cows may be more susceptible to infection by nematodes from giving birth up to 90 days post partum. However, adult cows, when wellmanaged, are not an important factor in the epidemiology of gastrointestinal nematodes, even in the post partum period.
\end{abstract}

Keywords: Bovine, gastrointestinal nematodes, periparturient, parasitic dynamics.

\footnotetext{
*Autor para correspondência: Rinaldo Batista Viana

Instituto da Saúde e Produçấo Animal,

Universidade Federal Rural da Amazônia - UFRA,

Av. Tancredo Neves, 251, Montese CEP 66077-530 Belém - PA, Brasil;

e-mail: rinaldo.viana@ufra.edu.br
} 


\section{Introdução}

Nas atividades pastoris, a produtividade está ligada ao desempenho integrado dos manejos: nutricional, sanitário, reprodutivo e qualidade genética dos animais (MALACCO, 2000). Dentre os fatores que contribuem para o baixo índice de produtividade da bovinocultura, a verminose ocupa um lugar de destaque e tem sido apontada como um dos importantes pontos de estrangulamento dos sistemas de produção de bovinos de corte e de leite (BIANCHIN; MELO, 1985).

$\mathrm{O}$ uso indiscriminado de drogas antiparasitárias pelos criadores, sem que se faça estudo sobre a prevalência do agente parasitário, tem provocado o aparecimento de resistência dos parasitos à ação dos medicamentos utilizados, podendo constituir-se em um dos principais problemas sanitários da produção animal (PAIVA et al., 2001). Outro fator que colabora para um ineficiente controle estratégico da verminose, estudado principalmente em ovelhas, é o fenômeno "Spring rise" ou quebra da imunidade no periparto, com o aumento do número de ovos de nematódeos por grama (OPG) de fezes no final do parto e início da lactação (BARGER, 1993). Essa queda na imunidade permite tanto o desenvolvimento de larvas em hipobiose como o maior estabelecimento de novas larvas e aumento da fecundidade de adultos pré-existentes (COSTA, 1983; BARGER, 1993).

O aumento do OPG no periparto também está relacionado com alteraçóes hormonais que ocorrem nessa fase reprodutiva (LLOYD, 1983). Lima e Guimarães (1992) verificaram esse aumento no OPG, a partir da $32^{\text {a }}$ semana de gestação, examinando 39 fêmeas da raça Nelore durante a gestação e lactação, embora não tenham determinado os parâmetros hormonais.

Bianchin e Honer (1985), estudando o período periparto, em 32 vacas da raça Nelore, encontraram tendência de aumento do OPG na época do parto e nas duas semanas pós-parto. Saueressig e Bianchin (1997), em vacas zebuínas e mestiças na região dos Cerrados, em Goiás, também relataram uma tendência de aumento de OPG por ocasião do parto e nas seis semanas seguintes, porém não registraram dados a respeito da idade dos animais e seus aspectos reprodutivos.

Gennari et al. (2002) observaram um aumento no OPG, nas primeiras semanas pós-parto, indicando que a queda da imunidade esteja ocorrendo por ocasião do parto ou algumas semanas pré-parto. Relataram, ainda, que vacas de primeira e segunda crias de raças leiteiras foram as maiores fontes de contaminação dos pastos, quando comparadas a vacas mais velhas, indicando que, com sucessivas infecçóes, as vacas vão se tornando mais resistentes a esses nematódeos, mesmo durante o período pré-parto.

O presente estudo foi realizado com o objetivo de investigar a dinâmica da eliminação de ovos por helmintos gastrintestinais, no periparto de vacas criadas no Nordeste Paraense, considerando-se o número de gestaçóes e o período gestacional.

\section{Material e Métodos}

O experimento foi realizado em uma propriedade localizada no município de Tomé-Açu, Mesorregião Nordeste Paraense, entre os meses de agosto de 2006 a janeiro de 2007, período correspondente à época seca na regiáo, quando ocorrem apenas chuvas ocasionais. Os animais eram criados em pastagens formadas por Brachiaria brizanta cv. Marandu e Brachiaria humidicula, adotando o sistema de pastejo rotacionado, recebendo ad libitum água e suplementação mineral (manafós núcleo 160: Fósforo160 g; Cálcio 175 g; Magnésio 20 g; Enxofre 36 g; Zinco 8.000 mg; Cobre $2.000 \mathrm{mg}$; Manganês 2.000 mg; Ferro 5.500 mg; Cobalto 200 mg; Iodo 90 mg; Selênio $36 \mathrm{mg}$; Flúor $1.600 \mathrm{mg}$ ).

Foram utilizadas 118 vacas distribuídas em dois grupos: G1, constituído por 55 vacas primíparas e de segunda cria (oito vacas da raça Guzerá, quatro vacas da raça Simental, 21 vacas da raça Simbrasil e 22 vacas mestiças); e G2, constituído de 63 vacas a partir da terceira cria (10 vacas da raça Guzerá, sete vacas da raça Simental, 18 vacas da raça Simbrasil e 28 vacas mestiças).

As vacas foram mantidas em piquetes com taxa de lotação de 1 UA.ha $^{-1}$, separando-se os animais em lotes de acordo com o grupo experimental. Os dois grupos (G1 e G2) eram rotacionados de acordo com a capacidade de suporte de cada piquete; desse modo, todos os animais tiveram acesso aos mesmos piquetes. Após o parto, as vacas foram agrupadas em piquetes maternidades, seguindo-se o mesmo sistema de rotação. Os piquetes tinham descanso de pastejo de 40 dias.

No início do estudo, as vacas apresentavam idade superior a 32 meses e não foram vermifugadas há cerca de oito meses, segundo o manejo adotado na propriedade (última vermifugação aos 24 meses com anti-helmínticos do grupo das lactonas macrocíclicas, ivermectina $1 \mathrm{~mL} / 50 \mathrm{kgpv}$ ).

Foram realizadas coletas de sangue e de fezes de cada animal, sendo quatro no período compreendido entre os 120 dias pré-parto e a parição, e três coletadas no período compreendido entre o parto e os 90 dias pós-parto, com intervalo de 30 dias entre as coletas. As amostras de fezes foram coletadas diretamente do reto para determinação do OPG, realizado pela técnica de Gordon e Whitlock (1939).

As amostras de sangue foram coletadas por punção da veia jugular externa, em tubos a vácuo, com anticoagulante EDTA-K a $15 \%$, para determinação do volume globular (VG) e a taxa de hemoglobina (Hb), segundo Birgel (1982).

Por ocasião da coleta de amostras, a condição do escore corporal (ECC) dos animais foi estimada de acordo com Houghton et al. (1990), classificando-se os escores em uma escala de um (magro) a cinco (gordo), sendo todas as avaliações feitas pelo mesmo avaliador. Possíveis diferenças nos valores de OPG, ECC, VG e $\mathrm{Hb}$ entre os grupos foram determinadas pelo teste de Qui-quadrado, com nível de significância de 95\% (p < 0,05).

\section{Resultados e Discussáo}

$\mathrm{Na}$ Tabela 1, estão representados os valores médios das variáveis estudadas no período periparto para os animais dos grupos G1 e G2.

Os valores de OPG foram baixos e semelhantes ( $\mathrm{p}>0,05)$ nos animais do grupo G1 e G2, com médias de 19,4 \pm 42,0 e $31,10 \pm 68,0$, respectivamente, indicando não haver diferença nos OPG nas vacas das diferentes idades. Gennari et al. (2002) observaram que animais de primeira e de segunda cria apresentaram OPG significativamente superior, quando comparados com vacas de terceira ou mais crias, entretanto as vacas daquele estudo eram 
Tabela 1. Médias, desvios padrão (dp), valores mínimos e máximos para as variáveis estudadas em vacas de corte primíparas e de segunda cria (G1) e com três ou mais crias (G2) no periparto. Mesorregião Nordeste Paraense, 2009.

\begin{tabular}{|c|c|c|}
\hline Variável & $\begin{array}{c}\text { G1 } \\
\text { média } \pm d p(\text { valor mínimo }- \text { máximo })\end{array}$ & $\begin{array}{c}\text { G2 } \\
\text { média } \pm \mathrm{dp}(\text { valor mínimo }- \text { máximo })\end{array}$ \\
\hline $\operatorname{ECC}(1-5)$ & $3,1 \pm 0,4(2,5-4,5)^{a}$ & $3,2 \pm 0,5(2-4,5)^{a}$ \\
\hline Volume Globular (\%) & $37,7 \pm 4,0(29,0-50,0)^{\mathrm{a}}$ & $37,5 \pm 4,5(19,9-49,0)^{a}$ \\
\hline Hemoglobina (g/dl) & $14,0 \pm 1,8(10,45-18,99)^{a}$ & $13,9 \pm 2,0(10,36-18,59)^{a}$ \\
\hline OPG & $19,4 \pm 42,9(0-250)^{\mathrm{a}}$ & $31,1 \pm 68,0(0-500)^{\mathrm{a}}$ \\
\hline
\end{tabular}

Letras diferentes, na mesma linha, indicam diferença significativa $(\mathrm{P}<0,05)$. ECC - Escore de condiçấo corporal; OPG - ovos por grama de fezes.

Tabela 2. Médias, desvios padrão (dp), valores mínimos e máximos para as avaliaçóes parasitárias e hematológicas de vacas de corte de primeira e segunda crias (G1) e de multíparas (G2) no período pré (120 dias pré-parto até o parto) e pós-parto (parto até 90 dias pós-parto). Mesorregião Nordeste Paraense, 2009.

\begin{tabular}{|c|c|c|c|c|}
\hline \multirow[t]{2}{*}{ Variável } & \multicolumn{2}{|c|}{$\begin{array}{c}\text { G1 } \\
\text { média } \pm \mathrm{dp}(\text { valor mínimo }- \text { máximo })\end{array}$} & \multicolumn{2}{|c|}{$\begin{array}{c}\text { G2 } \\
\text { média } \pm \mathrm{dp}(\text { valor mínimo }- \text { máximo })\end{array}$} \\
\hline & Pré-parto & Pós-parto & Pré-parto & Pós-parto \\
\hline $\operatorname{ECC}(1-5)$ & $3,3 \pm 0,4^{a}(2,5-4,5)$ & $3,0 \pm 0,3^{\mathrm{b}}(2,5-4,0)$ & $3,4 \pm 0,5^{a}(2,5-4,5)$ & $3,0 \pm 0,4^{\mathrm{b}}(2,0-4,0)$ \\
\hline VG (\%) & $38,7 \pm 3,6^{a}(32-50)$ & $36,3 \pm 4,0^{b}(29-46)$ & $38,6 \pm 4,1^{a}(19,9-49,0)$ & $35,9 \pm 4,4^{\mathrm{b}}(25-44)$ \\
\hline $\mathrm{Hb}(\mathrm{g} / \mathrm{dl})$ & $14,6 \pm 1,6^{a}(11,9-19,0)$ & $13,4 \pm 1,6^{\mathrm{b}}(10,4-17,6)$ & $14,5 \pm 2,0^{\mathrm{a}}(10,4-18,6)$ & $13,0 \pm 1,7^{b}(9,4-16,2)$ \\
\hline OPG & $9,7 \pm 26,9^{\mathrm{b}}(0-150)$ & $32,5 \pm 55,5^{a}(0-250)$ & $16,4 \pm 48,2^{b}(0-450)$ & $51,5 \pm 84,8^{a}(0-500)$ \\
\hline
\end{tabular}

Letras diferentes, na mesma linha para cada variável dentro do mesmo grupo $(\mathrm{G} 1$ e G2), indicam diferença significativa $(\mathrm{P}<0,05)$. ECC - Escore de condição corporal; VG - Volume globular; Hb - Hemoglobina; OPG - ovos por grama de fezes.

de raças leiteiras, Holandesas e Girolandas, diferentemente das raças de corte avaliadas no presente estudo.

Os valores de $\mathrm{Hb}$ e VG foram semelhantes entre os grupos e encontraram-se dentro dos valores de normalidade, resultados esperados pelos baixos valores de OPG observados.

Analisando-se o efeito do período gestacional (pré $\times$ pós-parto) sobre os valores hematológicos e de OPG das vacas do mesmo grupo, verificaram-se diferenças significativas ( $p<0,05)$, com menores valores de ECC, VG e Hb e maiores valores de OPG no período pós-parto para ambos os grupos (Tabela 2).

A diminuição observada no ECC no pós-parto era esperada, pois há uma tendência normal de diminuição da condição corporal nesse período, devido à perda de peso que os animais sofrem com a parição. Apesar de ter ocorrido redução no VG e Hb, estes permaneceram dentro dos limites de normalidade, não havendo, necessariamente uma relaçáo com a carga parasitária.

Aumento nos valores dos OPG também foram observados por Lima e Guimarães (1992) e por Saueressig e Bianchin (1997), em vacas de corte, por ocasião do parto, e por Gennari et al. (2002), no pós-parto, em animais de primeira e de segunda crias de raças leiteiras. Mesmo com aumentos na média de OPG no pós-parto, esses permaneceram baixos (32,5 e 51,5 OPG para o G1 e o G2, respectivamente) para a espécie, conforme consideraram Ueno e Gonçalves (1998).

Esse aumento do OPG no pós-parto, tanto no grupo G1 como no G2, sugere uma queda na imunidade por ocasiáo do parto, como anteriormente descrito (BORGSTEEDE, 1978; LLOYD, 1983; FLEMING; CONRAD, 1989; LIMA; GUIMARÃES, 1992; BARGER, 1993; GENNARI et al., 2002); todavia essa queda foi discreta, especialmente em vacas de origem Bos taurus indicus. $\mathrm{O}$ baixo valor de OPG obtido em ambos os tratamentos também reflete o adequado manejo adotado na propriedade.

\section{Conclusáo}

Os resultados obtidos sugerem que vacas adultas, mesmo no período periparto, quando bem manejadas, não constituem um fator importante na epidemiologia das verminoses gastrintestinais.

\section{Agradecimentos}

À Brasnorte Agropecuária pelo suporte financeiro dado a essa pesquisa e à Fazenda Dragão do Norte (Tomé-Açu), especialmente ao Sr. Elias Covre, pela permissão da utilização dos animais para realização desse estudo.

\section{Referências}

BARGER, I. A. Influence of sex and reproductive status on susceptibility of ruminants to nematode parasitism. International Journal Parasitology, v. 23, n. 4, p. 463-469, 1993.

BIANCHIN, I.; HONER, M. R. Produçáo de ovos de vermes gastrintestinais em vacas nelore, durante o período periparto. Campo Grande: EMBRAPA-CNPGC, 1985. Comunicado Técnico, n. 27.

BIANCHIN, I.; MELO, H. J. H. Epidemiologia e controle de helmintos gastrintestinais em bovinos de corte nos cerrados. 2 ed. Campo Grande: EMBRAPA-CNPGC, 1985. p. 60. Circular Técnica, n. 16.

BIRGEL, E. H. Hematologia Clínica Veterinária. In: BIRGEL, E. H.; BENESI, F. J. Patologia Clínica Veterinária. São Paulo: Sociedade Paulista de Medicina Veterinária, 1982. p. 2-34.

BORGSTEEDE, F. H. M. Observations on the Post-parturient Rise of Nematode Egg-output in Cattle. Veterinary Parasitology, v. 4, n. 4, p. 385-391, 1978. 
COSTA, C. A. F. Increase of gastro-intestinal nematode egg counts in lactating goats. Pesquisa Agropecuária Brasileira, v. 18, n. 8, p. 919-929, 1983.

FLEMING, M. W.; CONRAD, S. D. Effects of exogenous progesterone and/or prolactin on Haemonchus contortus infections in ovariectomized ewes. Veterinary Parasitology, v. 34, n. 1/2, p. 57-62, 1989.

GENNARI, S. M. et al. Determinação da Contagem de Ovos de Nematódeos no Período Peri-parto em Vacas. Brazilian Journal Veterinary Research Animal Science, v. 39, n. 1, p. 32-37, 2002.

GORDON, H. M.; WHITLOCK, H. V. A new technique for counting nematode eggs in sheep faeces. Journal of the Council for Scientific and Industrial Research, v. 12, p. 50-52, 1939.

HOUGHTON, P. L. et al. Effects of body composition, pre-and pospartum energy level and early weaning on reproductive performance of beef cows and preweaning calf gain. Journal of Animal Science, v. 68 , n. 5 , p. $1438-1446,1990$.

LIMA,W. S.; GUIMARĀES, M. P. Comportamento das infecçôes helmínticas em vacas de rebanho de corte durante a gestação e lactação.
Arquivo Brasileiro de Medicina Veterinária e Zootecnia, v. 44 n. 5 , p. 387-396, 1992.

LLOYD, S. Effect of pregnancy and lactation upon infection. Veterinary Immunology and Imunopathology, v. 4, n. 1-2, p. 153-176, 1983.

MALACCO, M. A. F. Controle Parasitário na Fêmea Bovina. [S.1.]: MERIAL Saúde Animal Ltda., 2000.

PAIVA, F. et al. Resistência a Ivermectina Constatada em Haemonchus placei e Cooperia punctata em Bovinos. A Hora Veterinária, v. 20, n. 120, p. 29-34, 2001.

SAUERESSIG, T. M.; BIANCHIN, I. Relação entre produção de ovos de nematódeos gastrintestinais e período peri-parto em vaca zebu e mestiças no Distrito Federal. Revista Brasileira de Parasitologia Veterinária, v. 6, n. 2, supl. 1, 1997.

UENO, K.; GONÇALVES, P. C. Manual para diagnóstico das helmintoses de ruminantes. 4 ed. Salvador: Japan International Cooperation Agency, 1998. 143 p. 